\title{
AEROMONAS ASSOCIATED DIARRHOEAL DISEASE IN SOUTH BRAZIL: PREVALENCE, VIRULENCE FACTORS AND ANTIMICROBIAL RESISTANCE
}

\author{
Ivani M. F. Guerra ${ }^{1}$; Raquel Fadanelli'; Manuela Figueirón'; Fernando Schreiner²; Ana Paula L. Delamare'; \\ Claudia Wollheim²; Sérgio Olavo P. Costa ${ }^{1,3}$; Sergio Echeverrigaray ${ }^{1 *}$
}

${ }^{1}$ Instituto de Biotecnologia, Universidade de Caxias do Sul, Caxias do Sul, RS, Brasil; ${ }^{2}$ Microbiologia Médica, Universidade de Caxias do Sul, Caxias do Sul, RS, Brasil; ${ }^{3}$ Universidade Católica de Santos, Santos, SP, Brasil

Submitted: December 11, 2006; Returned to authors for corrections: May 19, 2007; Approved: November 15, 2007.

\begin{abstract}
Aeromonas were isolated from 27 (6.6\%) of 408 patients admitted with acute gastroenteritis in two hospitals at Rio Grande do Sul, Brazil. Isolates were classified as A. hydrophila (51.8\%), A. caviae (40.8\%), and A. veronii biotype sobria (7.4\%). The highest prevalence of Aeromonas associated infections occurred in lactants and children. Virulence genes (aerA -aerolysin/hemolysin, ahpA -serine-protease, satA glycerophospholipid-cholesterol acyltransferase, lipA -lipase, and $a h y B$-elastase) and virulence factors (hemolytic, proteolitic, lipolitic activities, and biofilm formation) were identified in most $A$. hydrophila and $A$. veronii biotype sobria isolates, with lower frequencies on A. caviae. All Aeromonas isolates were resistant to ampicillin, ticarcillin/clavulanic acid, cephalotin, and cephazolin, and most of them (>70\%) exhibited resistance to imipenem, carbenicillin, amoxillin/sulbactan, and piperacillin. Multiple-resistance, more than four antibiotics, was evidenced in $29.6 \%$ of the isolates. The most efficient antibiotics were the quinolones (ciprofloxacin and norfloxacin), and the aminoglycosides (amikacin and netilmicin).
\end{abstract}

Key words: Aeromonas, diarrhea disease, virulence factors, antimicrobial resistance

\section{INTRODUCTION}

Diarrhea disease is an important cause of morbidity and mortality in developing countries, particularly in infants and elders. Diarrheas are caused by viral, bacterial, and parasitic infections, as well as food intolerances, reaction to medicines, and other physiological and immunological disorders (2). Bacterial infections are responsible for $20-40 \%$ of diarrhea illness, and several bacterial species have been frequently ascribed to diarrhea episodes, including Campylobacter jejuni, Escherichia coli, Salmonella spp., Vibrio cholerae, Yersinia enterocolitica, Aeromonas spp., and Plesiomonas spp.

In the last decades, Aeromonas have been increasingly recognized as relevant etiological agents in gastrointestinal infections $(14,24,30)$, as well as extraintestinal infections such as cellulitis, wound infections, septicemia, urinary tract infections, among others (2). Three Aeromonas species, A. hydrophila, A. caviae, and A. veronii biotype sobria are considered of clinical significance $(2,14)$.

The virulence of Aeromonas is multifactorial, including adhesions, S-layer, lipopolyssaccharides, siderophores, and an array of exoenzymes and exotoxins, i.e. aerolysin/hemolysin, lipases, proteases, among others $(24,26,32)$. Genes encoding these virulence factors have been isolated and sequenced allowing the detection of signature regions of these genes and the evaluation of their presence in Aeromonas clinical and environmental isolates $(5,6)$. Moreover, the regulation and secretion processes of viralence factors, as well as the host response alter the pathogenicity of Aeromonas $(10,27,28)$.

Antimicrobial resistance among enteric pathogens is a serious problem in developing countries where there is a high frequency of gastroenteric illness and many antibiotics fall routinely into inadequate use. Antibiotic resistance is particularly relevant in pathogenic Aeromonas species in which,

*Corresponding Author. Mailing address: Instituto de Biotecnologia, Universidade de Caxias do Sul, R. Francisco G. Vargas 1130, Caxias do Sul, 95001970, Rio Grande do Sul, Brasil. Tel.: 005554 32182149. E-mail: selaguna@yahoo.com 
besides the classical resistance to $\beta$-lactamic antibiotics, multiple-resistance has been frequently identified $(11,15,29,30)$. These bacteria can receive and transfer antibiotic resistance genes to other Gram negative bacteria (17).

The aim of this study was to determine the prevalence of Aeromonas species among patients hospitalized with diarrhea disease in Rio Grande do Sul, Brazil, as well as to determine the antibiotic resistance patterns and the presence of virulence factors among Aeromonas isolates.

\section{MATERIALS AND METHODS}

A total of 408 stool specimens were collected from patients admitted with diarrhea disease, between January 1999 and Dezember 2000, in two hospitals of Rio Grande do Sul, Brazil: Hospital Geral of Caxias do Sul, and Hospital São Lucas of Porto Alegre. A diarrheic subject was identified as someone suffering three or more episodes of watery or loose discharges in a $24 \mathrm{~h}$ period prior to admission in the hospital. As control, 70 stool samples form infants ( 0 to 2 years), 50 from children ( 2 to 10 years), 50 form adults ( $<60$ years), and 42 from elderly, were collected from non-hospitalized apparently healthy subjects. Clinical reports of all patients and controls were recorded on a standard form, including personal data, clinical history, diarrhea intensity and overt clinical conditions (fever, nausea, vomiting and dehydration status).

Stool specimens were diluted $(0.5 \mathrm{~g} / 10 \mathrm{ml})$ in alkaline peptone water ( $1 \%$ peptone, $1 \% \mathrm{NaCl}, \mathrm{pH} 8.6)$. Aliquots $(0.1 \mathrm{ml})$ were plated on Ampicillin Sheep-blood Agar medium (ASA-blood agar base supplemented with $5 \%$ sheep blood and $10 \mathrm{mg} / \mathrm{L}$ ampicillin) and Yersinia Selective Agar medium (YSA), and incubated at $28^{\circ} \mathrm{C}$ for $24 \mathrm{~h}$ and $48 \mathrm{~h}$. Hemolytic colonies on ASA medium with a characteristic creamy aspect and light brown color, or purple colonies with a deep purple halo in YSA medium, were streaked on Trypticase Soy Agar (TSA) and incubated for $24 \mathrm{~h}$ at $37^{\circ} \mathrm{C}$. These isolates were tested for oxidase activity, and if proved positive were stored in TSA slants at room temperature, and in Brain Heart Infusion (BHI) supplemented with $25 \%$ glycerol at $-70^{\circ} \mathrm{C}$. All culture media were purchased from Merck, except BHI, from Difco.

Biochemical tests for identification of Aeromonas species were performed according to the AerokeyII system (4). All samples were examined for other common enteric pathogens following standard procedures (13).

The following Aeromonas reference strains were used: ATCC 7966 and CECT 398 (A. hydrophila), ATCC 43979 (A. veronii biotype sobria), ATCC 15468 and ATCC 14486 (A. caviae), ATCC 35624 (A. veronii var. veronii), ATCC 33907 (A. media), and ATCC 23309 (A. eucrenophila).

Antibiotic susceptibility testing was performed by the disk diffusion method (7). Aeromonas strains were examined for resistance against a panel of 24 antibiotics, including representatives of the most important classes: amikacin, ampicillin, amoxillin/sulbactam, ticarcillin/clavulanic acid, piperacillin, aztreonam, carbenicillin, cephalothin, cephazolin, cefuroxime, cefoperazone, cefotaxime, ciprofloxacin, ceftazidime, ceftriaxone, tetracycline, chloramphenicol, trimethoprim/sulfamethoxazole, streptomycin, gentamycin, imipenem, netilmicin, norfloxacin, and tobramycin. Zones of inhibition were measured after $24 \mathrm{~h}$ incubation at $37^{\circ} \mathrm{C}$, and susceptibility/resistance interpretation were performed according to CLSI for enterobacteria (7). Aeromonas strains ATCC 7966, ATCC 43979, and ATCC 15468, and Escherichia coli (ATCC 25922) and Staphylococcus aureus (ATCC 25923), were included as quality controls.

Hemolytic positive isolates were identified by the presence of clear ( $\beta$-hemolysis) or diffuse ( $\alpha$-hemolysis) halos around the colonies grown at $37^{\circ} \mathrm{C}$ for $24 \mathrm{~h}$ on TSA agar (Difco) containing $5 \%$ rabbit or $5 \%$ human blood. To determine the proteolytic activity Aeromonas isolates were striped on TSA agar containing gelatin $(1 \%)$, grown for $24 \mathrm{~h}$ at $30^{\circ} \mathrm{C}$, and developed by the addition of a saturate solution of ammonium sulfate. Lipase activity was assay by the Tween-calcium method (19), and biofilm formation was evaluated by the method proposed by Heilmann et al. (12).

The presence of the genes aerA (aerolysin/hemolysin), ahpA (serine-protease), satA (GCTA-glycerophospholipid-cholesterol acyltransferase), lipA (lipase), and $a h y B$ (elastase) was evaluated by PCR amplification using the primers and procedures previously proposed $(5,6)$.

\section{RESULTS AND DISCUSSION}

Potentially gastroenteric bacteria, as well as other bacteria, were isolated from $47(11.5 \%)$ out of 408 stool specimens obtained from patients admitted with acute diarrhea in two hospitals of Rio Grande do Sul, Brazil. Aeromonas prevalence corresponded to $6.6 \%$ with a total of 27 isolates, significantly different from $0.0 \%$ in the 212 control stool samples evaluated. Twenty one samples exhibited just Aeromonas, and six samples showed Aeromonas associated with E. coli (2 samples), Salmonella (2 samples), P. aeruginosa (1 sample) and Klebsiella (1 sample). Escherichia coli, Salmonella sp., and other bacteria (Shigella, Pseudomonas, and Klebsiella) were identified in $2.7 \%$, $1.5 \%$, and $0.7 \%$ of the samples, respectively. The prevalence of Aeromonas is consistent with that previously reported $(16,20,22,30)$. However, the frequency of Aeromonas in comparison with other enteric bacteria was higher to that previously reported in several countries, including Brazil (22). The presence of more than one enteric bacteria was evidenced in $15 \%$ of the patients, a frequency lower than that reported in other South-American countries (23).

The highest prevalence of Aeromonas (14.3\%) was observed in lactants ( $<1$ years old), decreasing to $9.5 \%$ in $1-2$ years old children, to $5.7 \%$ in $2-10$ years old children, $2.7 \%$ in adults, and 
7.3\% in elders (Table 1). High frequency of Aeromonas in infants and elder were reported by several authors $(9,16,22,31)$. Although not completely understood, this fact has been attributed to intrinsic physiological and immunological characteristics of infants and elder, associated with the presence of Aeromonas in food and beverages $(2,18)$.

Three species of Aeromonas were identified among the 27 isolates: $14(51.8 \%)$ were classified as A. hydrophila, $11(40.8 \%)$ as A. caviae, and $2(7.4 \%)$ as A. sobria. These data different from those obtained at Rio de Janeiro $(8,9)$, and at Goiânia (22), both in the tropical region of Brazil, in which Aeromonas caviae was the most prevalent species.

Analyzing the clinical reports, $51.9 \%$ of the cases associated with Aeromonas could be classified as toxigenic (watery diarrhea with rare abdominal cramps, nausea and vomiting), and $48.1 \%$ as dysenteric (loose and bloody stools, strong abdominal cramps, fever, nausea and vomiting), which is consistent with other reports $(3,16,30)$.

Table 1. Frequency of Aeromonas strains from fecal specimens according to patients age.

\begin{tabular}{lccc}
\hline Patient age & $\begin{array}{c}\mathrm{N}^{\mathrm{o}} \text { of cases } \\
\text { evaluated }\end{array}$ & $\begin{array}{c}\mathrm{N}^{\mathrm{o}} \text { of Aeromonas } \\
\text { positive cases }\end{array}$ & $(\%)$ \\
\hline Under 1 year & 56 & 8 & 14.3 \\
1-2 years old & 63 & 6 & 9.5 \\
2-10 years old & 87 & 5 & 5.7 \\
Adults (up to & & 4 & 2.7 \\
60 years) & 147 & 4 & 7.3 \\
\hline Elderly & 55 & 27 & 6.6 \\
\hline Total & 408 & & \\
\hline
\end{tabular}

The gene encoding the aerolysin/hemolysin (cytotoxic enterotoxin) was detected in 20 isolates $(74.1 \%)$, with no significant difference at the species level (Table 2). This frequency is similar to that previously reported on clinical isolates of these bacterial species (6). All the isolates that harbor the aerA gene exhibited hemolytic activity on human blood. However, despite the presence or absence of the aerA gene, all the isolates showed $\beta$-hemolytic activity on rabbit blood, fact that may be associated to the presence of other hemolysin genes such as hlyA (32).

All the isolates obtained from patients with toxigenic diarrhea harbor the aerA gene, supporting the idea that aerolysin is an important virulence factor associated with watery diarrhea caused by Aeromonas species (3).

The serine protease gene ( $a h p A)$ was detected in $63.0 \%$ of the isolates (Table 2), a frequency $10 \%$ lower than that previously reported (6). The serine protease has been associated with the activation of aerolysin (2) and other extracellular enzymes, thus affecting the overall virulence of Aeromonas strains. In this sense it is important to note that all the aerA positive isolates associated with toxigenic diarrhea were also positives for the serine protease gene, whereas the ahpA gene was present in only $23 \%$ of the isolates obtained from dysenteric samples.

Moreover, twenty-four isolates (88.9\%) were positives for the ahyB gene that codes for a metalloprotease (elastase), considered one of the most important virulence factors (5). Lipase and glycerophospholipid-cholesterol acyltransferase genes (lipA and satA) were detected in $96.3 \%$ of the isolates (Table 2). Glycerophospholipid-cholesterol acyltransferases and lipases have been associated with intestinal damage and interaction with human leukocytes, respectively (6).

Biofilm formation, a character that can influence the was detected in $71.4 \%$ of A. hydrophila isolates. Aeromonas

Table 2. Prevalence of virulence factors and genes among Aeromonas isolates.

\begin{tabular}{lccc}
\hline & A. hydrophila $(\mathbf{n}=\mathbf{1 4})$ & A. caviae $(\mathbf{n = 1 1})$ & A. veronii biovar. sobria $(\mathbf{n}=\mathbf{2})$ \\
\hline Virulence factors & & & \\
Hemolytic activity (human blood) & $12(85.7 \%)$ & $6(54.5 \%)$ & $2(100 \%)$ \\
Hemolytic activity (rabbit blood) & $14(100 \%)$ & $8(72.7 \%)$ & $2(100 \%)$ \\
Proteolytic activity & $14(100 \%)$ & $11(100 \%)$ & $2(100 \%)$ \\
Lipolytic activity & $14(100 \%)$ & $10(91 \%)$ & $2(100 \%)$ \\
Biofilm & $10(71.4 \%)$ & $3(27.3 \%)$ & $1(50 \%)$ \\
Virulence genes & & & \\
Aerolysin (aerA) & $11(78.6 \%)$ & $7(63.6 \%)$ & $2(100 \%)$ \\
Serine protease $($ ahpA $)$ & $11(78.6 \%)$ & $5(45.4 \%)$ & $1(50 \%)$ \\
Elastase (ahyB) & $12(85.7 \%)$ & $10(91 \%)$ & $2(100 \%)$ \\
Lipase $($ lipA $)$ & $14(100 \%)$ & $10(91 \%)$ & $2(100 \%)$ \\
GCAT (satA) & $14(100 \%)$ & $10(91 \%)$ & $2(100 \%)$ \\
\hline
\end{tabular}


biofilms are associated with putative virulence proteins implicated in polar flagellar assembly and bacterial adhesion to host tissues (33).

The expression of several putative virulence factors and genes in all the isolates can be seen as an indicative of pathogenic potential of these clinical isolates. Comparisons between clinical and environmental isolates of Aeromonas have shown that the formers present a higher frequency of virulence genes and exhibited a higher proportion of virulence factors $(6,8)$.

Considering the importance of antibiotic resistance in the treatment of diarrhea diseases, the 27 Aeromonas isolated in this study were tested for antibiotic susceptibility. As can be observed in Table 3, all the isolates were sensitive to amikacin, norfloxacin, netilmicin, and ciprofloxacin. Aeromonas susceptibility to these drugs has been previously reported $(15,29)$. Most of the isolates $(>80 \%)$ were susceptible to aztreonam, cefoperazone, ceftriazime, gentamicin, and chloramphenicol.

Conversely, all the isolates were resistant to ampicillin, cephalotin, cephazolin, and ticarcillin/clavulanic acid (Table 3), and most of them were also resistant to amoxillin/subactam (92.6\%), piperacillin (81.5\%), imipenem (77.8\%), and carbenicillin (74\%). The large spectra of resistance to $\beta$-lactam antibiotics, the resistance to imipenem (a drug highly stable to serine- $\beta$ lactamases), as well as the inefficiency of clavulanic acid and sulbactam to inhibit Aeromonas $\beta$-lactamases, corroborate previous results indicating the chromosomally mediated production of metallo- $\beta$-lactamases by these bacteria $(21,25)$. Furthermore, beyond the penicillins and first generation cephalosporins, some isolates (18.5\%) showed resistance to several new extended-spectrum cephalosporins, and one isolate of $A$. hydrophila exhibited resistance to aztreonam and all the penicillins and cephalosponins.

Some isolates could be considered as multi-resistant, as they stand to more than four antibiotics other than the $\beta$-lactam. In this sense, one isolate exhibited resistance to seven antibiotics including three aminoglycosides, tetracycline, chloramphenicol, and trimethoprim/sulfamethoxazole), two were resistant to streptomycin, tetracycline, chloramphenicol and trimethoprim/ sulfamethoxazole, two were resistant to four aminoglycosides, and three were resistant to tetracycline and trimethoprim/ sulfamethoxazole. Similar multiple antibiotic resistance patterns in Aeromonas were reported $(8,11,15,29)$, indicating that this is a common and concerning feature of these bacteria, specially considering their ability to efficiently receive and transmit antibiotic resistance genes to other enteric species (17).

In conclusion, the data obtained in this study strongly convey the need to consider Aeromonas as an important causative agent of acute diarrhea disease in South Brazil, particularly among infants and children. The presence of several virulence factors and genes, and the occurrence of multidrug
Table 3. Antibiotic resistance of 27 isolated Aeromonas strains.

\begin{tabular}{llcc}
\hline CLASS & ANTIBIOTICS & NR & $\begin{array}{c}\text { Resistant } \\
(\%)\end{array}$ \\
\hline 3- lactam antibiotics & & & \\
1. Penicillins & CBN & 20 & 74.1 \\
& AMN & 27 & 100.0 \\
& AXS & 25 & 92.6 \\
& CXT & 27 & 100.0 \\
2. Monobactams & PPN & AZM & 81.5 \\
3. Cephalosporins & CEF $\left(1^{\text {st }}\right.$ generation $)$ & 27 & 3.7 \\
& CZN $\left(1^{\text {st }}\right.$ generation $)$ & 27 & 100.0 \\
& CXN $\left(2^{\text {nd }}\right.$ generation $)$ & 9 & 33.3 \\
& CRE $\left(2^{\text {nd }}\right.$ generation $)$ & 4 & 14.8 \\
& CPN $\left(3^{\text {th }}\right.$ generation $)$ & 1 & 3.7 \\
& CRO $\left(3^{\text {th }}\right.$ generation $)$ & 1 & 3.7 \\
4. Carbapenem & CAE $\left(3^{\text {th }}\right.$ generation $)$ & 5 & 18.5 \\
Aminoglycosides & IMI $\left(3^{\text {th }}\right.$ generation $)$ & 2 & 7.4 \\
& AMI & 21 & 77.8 \\
& GEN & 0 & 0 \\
NET & 4 & 14.8 \\
Tetracycline & TOB & 0 & 0 \\
Chloramphenicol & STR & 9 & 33.3 \\
Quinolones & CLO & 8 & 29.6 \\
& CIP & 14 & 51.8 \\
& NOR & 4 & 14.8 \\
& SXT & 0 & 0 \\
& & 0 & 0 \\
& & 13 & 48.1 \\
\hline
\end{tabular}

NR: number of antimicrobial resistant strains

$\mathrm{CBN}=$ carbenicillin; $\mathrm{AMN}=$ ampicillin $; \mathrm{AXS}=$ amoxillin/sulbactam; $\mathrm{CXT}=$ ticarcillin/clavulanic acid; $\mathrm{PPN}=$ piperacillin; $\mathrm{AZM}=$ aztreonam; $\mathrm{CEF}=$ cephalothin; $\mathrm{CZN}=$ cephazolin; $\mathrm{CXN}=$ cefoxitin CRE= cefuroxime; $\mathrm{CPN}=$ cefoperazone $\mathrm{CRO}=$ ceftriaxone $\mathrm{CAE}=$ cefotaxime; $\mathrm{CDE}=$ ceftazidime $; \mathrm{IMI}=$ imipenem $; \mathrm{AMI}=$ amikacin $; \mathrm{GEN}=$ gentamicin: $\mathrm{NET}=$ netilmicin: $\mathrm{TOB}=$ tobramycin; $\mathrm{STR}=$ streptomycin; $\mathrm{TET}=$ tetracycline: $\mathrm{CLO}=$ chloramphenicol: $\mathrm{CIP}=$ ciprofloxacin; $\mathrm{NOR}=$ norfloxacin; $\mathrm{SXT}=$ trimethoprim/sulfamethoxazole.

resistance in Aeromonas isolates, highlights the necessity to implement routine identification of Aeromonas species, and continuous monitoring their antibiotic resistance pattern.

\section{ACKNOWLEDGEMENTS}

The authors want to thank the financial support of the Foundation of the University of Caxias do Sul, FAPERGS, CNPq and CAPES. 


\section{RESUMO}

\section{Aeromonas associadas a diarréias no sul do Brasil: prevalência, fatores de virulência, e resistência a antibióticos}

Aeromonas foram isoladas de 27 (6.6\%) dos 408 pacientes admitidos com gastroenterite aguda em dois hospitais do Rio Grande do Sul, Brasil. Os isolados foram classificados com $A$. hydrophila (51.8\%), A. caviae (40.8\%), e A. veronii biotype sobria (7.4\%). A maior prevalência de Aeromonas ocorreu em lactantes e crianças. Genes (aerA -aerolisina/hemolisina, ahpA -serina-protease, satA - glicerofosfolipidio-colesterol aciltransferase, lipA -lipase, e $a h y B$-elastase) e factores (atividade hemolítica, proteolítica, lipolítica, e formação de biofilme) de virulência foram identificados na maioria dos isolados de A. hydrophila e A. veronii biotype sobria, com freqüências menores em A. caviae. Todos os isolados de Aeromonas apresentaram resistência a ampicilina, ticarcilina/ ácido clavulânico, cefalotina e cefazolina, e a maior parte (>70\%) exibiram resistência a imipenem, carbenicilina, amoxacilina/ sulbactam e piperacilina. Resistência múltipla foi evidenciada em 29,6\% dos isolados. Os antibióticos mais eficientes foram as quinolonas (ciprofloxacina e norfloxacina) e os aminoglicosídicos (amicacina e netilmicina).

Palavras-chave: Aeromonas, diarréia, fatores de virulência, resistência antimicrobiana

\section{REFERENCES}

1. Abbott, S.L. (2003). Aeromonas and Plesiomonas. In: Murray, P.R.; Baron, E.J.; Pfaller, M.A.; Tenover, F.C.; Yorken, R.H. (eds) Manual of Clinical Microbiology, $8^{\text {th }}$ edn, Amercican Society for Microbiology, Washington.

2. Abrami, L.; Firaz, M.; Decroly, E.; Seidah, N.; Jean, J.; Thomas, G. (1998). The pore forming toxin aerolysin is activated by furin. $J$. Biol. Chem., 271: 32656-32661.

3. Albert, M.J.; Anzaruzzaman, M.; Kaisar, A.; Chopra, A.K.; Kuhn, I.; Rahman, M.; Faruque, A.S.G.; Islam, M.S.; Sack, R.B.; Mollby, R. (2000). Prevalence of enterotoxin genes in Aeromonas spp. Isolated from children with diarrhea, healthy controls, and the environment. J. Clin. Microbiol., 38, 3785-90.

4. Carnahan, A.M.; Behram, S.; Joseph, S.W. (1991). Aerokey II: a flexible key for identifying clinical Aeromonas species. J. Clin. Microbiol., 29, 2843-2849.

5. Cascón, A.; Yugueros, J.; Temprano, A.; Sánchez, M.; Hernanz, C.; Luengo, J.M.; Naharro, G. (2000). A major secreted elastase is essential for pathogenicity of Aeromonas hydrophila. Infect. Immun., 68, 3222-3241.

6. Chacón, M.R.; Figueras, M.J.; Castro-Escarpulli, G.; Soler, L.; Guarro, J. (2003). Distribution of virulence genes in clinical and environmental strains of Aeromonas spp. Antonie van Leeuwenhoek, 84, 269-278.

7. CLINICAL AND LABORATORY STANDARDS INSTITUTE. (2005). Perforamance standards for antimicrobial susceptibility testing, $15^{\text {th }}$ informational supplement. CLSI/NCCLS document M100-S15. Wayne, PA: National Committee for Clinical Laboratory Standards.
8. Freitas, A.C.; Freitas-Almeida, A.C.; Nunes, M.P.; Ricciardi, I.D. (1993). Aeromonas species isolated from human urine; biological characterization and antibiotic susceptibility. Rev. Microbiol., 24, 203-206.

9. Freitas, A.C.; Souza, S.M.S.; Macedo, L.C.; Pinto, E.C.; Pereira, S.S. (1998). Aeromonas species associated with gastroenteritis in children: prevalence, characteristics and virulence properties. Rev. Microbiol., 29, 152-157.

10. Galindo, G.L.; Sha, J.; Fadl, A.A.; Pillai, L.; Chopra, A.K. (2006). Host immune responses to Aeromonas virulence factors. Curr. Immunol. Rev., 2, 13-26.

11. Goñi-Urriza, M.; Pineau, L.; Capdepuy, M.; Roques, C.; Caumette, P.; Quentin, C. (2000). Antimicrobial resistanse of mesophilic Aeromonas spp. isolated from two European rivers. J. Antimicrob. Chemother, 46L, 297-301.

12. Heilmann, C.; Schweitzer, O.; Gerke, C.; Vanittanakom, N.; Mack, D.; Gotz, F. (1996). Molecular basis of intercellular adhesion in the biofilm-forming Staphylococcus epidermidis. Mol. Microbiol., 20, 1083-1091.

13. Icenberg, H.D. (2004). Clinical Microbiology Procedures Handbook, 2nd edn. Washington DC: Am. Soc. Microbiol. Press.

14. Janda, J.M.; Abbott, S.L. (1998). Evolving concepts regarding the genus Aeromonas: an expanding panorama of species, disease presentations, and unanswered questions. Clin. Infect. Dis., 27, 332344.

15. Kampfer, P.; Christmann, C.; Swing, J.; Huys, G. (1999). In vitro susceptibilities of Aeromonas genomic species to 69 antimicrobial agents. Syst. Appl. Microbiol., 22, 662-669.

16. Longa, A.; Vizcaya, L.; Nieves, B.; Hernández, J.; Pérez, I. (1996). Especies de Aeromonas asociadas a diarrea: Características microbiológicas y clínicas. Bol. Soc. Venez. Microbiol., 16, 13-18.

17. Marchandin, H.; Godreuil, S.; Darbas, H.; Jean-Pierre, H.; JumasBilak, E.; Chanal, C.; Bonnet, R. (2003). Extended-spectrum $\beta$ lactamase TEM-24 in an Aeromonas clinical strain: acquisition from the prevalent Enterobacter aerogenes clone in France. Antimicrob. Agents Chemother., 47, 3994-3995.

18. Melas, D.S.; Papageorgiou, D.K.; Mantis, A.I. (1999). Enumeration and confirmation of Aeromonas hydrophila, Aeromonas caviae, and Aeromonas sobria isolated from raw milk and other milk products in Northern Greece. J. Food Prot., 62, 463-466.

19. Michelim, L.; Lahude, M.; Araújo, P.R.; Giovanaz, D.S.H.; Muller, G.; Delamare, A.P.L.; Costa, S.O.P.; Echeverrigaray, S. (2005). Pathogenicity factors and antibiotic/chemotherapeutic resistance of Staphylococcus epidermidis associated with nosocomial infections occurring in intensive care units. Braz. J. Microbiol., 36, 17-23.

20. Morena, L.M.; Van, R.; Singh, K.; Brian, M.; Murray, E.B.; Pickering, K.L. (1993). Diarrhea associated with Aeromonas species in children in day care centers. J. Infect. Dis., 168, 215-218.

21. Morita, K.; Watanabe, N.; Murata, S.; Kanamori, M. (1994). $\beta$ lactam resistance of motile Aeromonas isolates from clinical and environmental sources. Antim. Agents Chem., 38, 353-355.

22. Nojimoto, I.T.I.; Bezana, C.S.C.; Carmo, C.; Valadão, L.M.; Carrijo, K.M. (1997). Prevelência de Aeromonas spp. em fezes diarréicas de crianças menores de 5 anos de idade na cidade de Goiânia, Goiás, no biênio 1995-1996. Rev. Soc. Bras. Méd. Trop., 30, 385-388.

23. Pazzaglia, G.; Sack, R.B.; Salazar, E.; Chea, E.; Leon-Barua, R.; Guerrero, C.E.; Palomino, J. (1991). High frequency coinfecting enterophatogens in Aeromonas associated diarrhea of hospitalized Peruvian infants. J. Clin. Microbiol., 29, 1151-1156.

24. Pemberton, J.M.; Kidd, S.P.; Schmidt, R. (1997). Secreted enzymes of Aeromonas. FEMS Microbiol. Lett., 152, 1-10.

25. Quiroga, M.I.; Franceschini, N.; Rossolini, G.M.; Gutkind, G.; Bonfiglio, G.; Franchino, L.; Amicosante, G. (2000). Interaction of cefotetan and the metallo-b-lactamases produced in Aeromonas spp. and in vitro activity. Chemotherapy, 46, 177-183. 
26. Sha, J.; Kolzlova, E.V.; Chopra, A.K. (2002). Role of various enterotoxins in Aeromonas hydrophila-induced gastroenteritis: generation of enterotoxin gene-deficient mutants and evaluation of their enterotoxic activity. Infect. Immun., 70, 1924-1935.

27. Sha, J.; Kozlova, E.V.; Fadl, A.A.; Olano, J.P.; Houston, C.V.; Peterson, J.W.; Chopra, A.K. (2004). Molecular characterization of a glucoseinhibited division gene, gidA, that regulates cytotoxic enterotoxin of Aeromonas hydrophila. Infect. Immun., 72, 1084-1095.

28. Sha, J.; Pillai, L.; Fadl, A.A.; Galindo, C.L.; Erova, T.E.; Chopra, A.K. (2005). The type III secretion system and cytotoxic enterotoxin alter the virulence of Aeromonas hydrophila. Infect. Immun., 73, 6446-6457.

29. Vila, J.; Marco, F.; Soler, M.; Chacón, M.; Figueras, M.J. (2002). In vitro antimicrobial susceptibility of clinical isolates of Aeromonas caviae, Aeromonas hydrophila, and Aeromonas veronii biotype sobria. J. Antimicrob. Chemoth., 49, 701-702.
30. Vila, J.; Ruiz, J.; Gallardo, J.; Vargas, M.; Soler, L.; Figueras, M.J.; Gascón, J. (2003). Aeromonas spp. and traveler's diarrhea: clinical features and antimicrobial resistance. Emerg. Infect. Dis., 9, 552555.

31. Wilcox, M.H.; Cook, A.M.; Eley, A.; Spencer, R.C. (1992). Aeromonas spp. as a potential cause of diarrhea in children. J. Clin. Pathol., 45, 95-96.

32. Wong, C.Y.F.; Heuzenroeder, M.W.; Flower, R.L.P. (1998) Inactivation of two haemolytic toxin genes in Aeromonas hydrophila attenuates virulence in a suckling mouse model. Microbiology, 144 291-298.

33. Yu, H.B.; Zhang, Y.L.; Lau, Y.L.; Yao, F.; Vilches, S.; Merino, S.; Tomas, J.M.; Howard, S.P.; Laung, K.Y. Identification and characterization of putative virulence genes and gene clusters in Aeromonas hydrophyla PPD134/91. Appl. Environ. Microbiol., 71, 4469-4477. 